\title{
The Action of the Ciliates of the Sheep's Rumen upon Various Water-soluble Carbohydrates, Including Polysaccharides
}

\author{
By FRANCES M. MASSON AND A. E. OXFORD
}

The Rowett Research Institute, Bucksburn, Aberdeenshire

\begin{abstract}
SUMMARY: When holotrich ciliates of hay-fed sheep's rumen acted upon watersoluble carbohydrates under conditions comparable with those in the rumen save for the absence of appreciable bacterial competition, only glucose, fructose, sucrose, inulin, bacterial levan (from Bacillus megatherium) and to a lesser extent cellobiose were utilized for rapid and extensive storage of iodophilic polysaccharide granules (cf. Oxford, 1951). No other soluble carbohydrate tried (including maltose) was so utilized. When polysaccharide storage did take place the product always gave a purple colour with iodine, and had the properties of a starch rather than glycogen in that it gave an insoluble iodine complex under the conditions of Pucher, Leavenworth \& Vickery (1948). Storage of starch by oligotrich ciliates was much slower than with holotrichs, and did not take place with cellobiose as substrate. Holotrich ciliates continued to replace themselves in the sheep's rumen even when large volumes of rumen contents were periodically withdrawn over a long period. The protozoan starch could be isolated in about $1 \%$ yield by application of the Pucher et al. (1948) method direct to the dry matter of strained rumen liquor taken from sheep which had grazed on starch-free Spring grass.
\end{abstract}

The ciliate literature contains numerous references to the storage of polysaccharides variously termed glycogen, starch, paraglycogen, paramylum, etc. (cf. Doyle, 1943; Kudo, 1947), but these iodine-staining inclusions have never been isolated in sufficient quantity to allow proper chemical investigation of them. The observation made previously (Oxford, 1951) that the holotrich ciliates of sheep fed on a starch-free diet (hay) stored relatively enormous numbers of tiny iodophilic polysaccharide granules when glucose, for example, was fermented in vitro by muslin-strained rumen liquor, has now been utilized in the preparation of a large specimen (more than $50 \mathrm{~g}$.) of this polysaccharide in a relatively pure state in order that such a chemical investigation might be made, beginning with a decision between the starch and glycogen possibilities.

In these in vitro fermentations the protozoa were, of course, competing with bacteria for the available sugar, and the yield of protozoan starch was never more than 5-10\% of the total sugar fermented. Attempts were, therefore, made to use an inoculum consisting mainly of protozoa, not only to minimize bacterial interference in order to obtain larger overall yields of protozoan starch, but also to find out which carbohydrates other than glucose, fructose and sucrose can be converted into starch by the protozoa acting alone. Owing to the difficulties of large-scale isolation of protozoa from rumen liquor without impairment of their fermentative powers, the first objective (greater overall yield) has not been attained, but the second, which obviously does not depend on the isolation of the greater part of the protozoa 
in rumen liquor, has largely been achieved and forms the main subject of this paper.

The experience gained was further applied to the direct isolation of protozoan starch from the rumen contents of grass-fed sheep. This is of some importance because it is well known that lush Spring grass, which is relatively rich in water-soluble carbohydrates and protein but almost free from starch, supports the greatest density of protozoan population in the rumen.

\section{METHODS}

Animals. Rumen-fistulated sheep Nos. 272 and 337 were used as previously described (Oxford, 1951). They were fed exclusively on meadow hay. In addition three unfistulated Cheviot ewes, each 1 year old, were put to grass from May to August and killed when required.

Fermentation procedures. In the large-scale preparation of protozoan starch the methods described by Oxford (1951) were modified as follows: (a) The fermentation time was decreased to $3 \mathrm{hr}$. This was sufficient for maximum starch storage in holotrichs but not in oligotrichs, for which an overnight fermentation is better. The separation of heavy holotrichs unmixed with oligotrichs was therefore facilitated. (b) The initial glucose concentration was decreased to $0.5 \%$. (c) Soft tap-water was used instead of distilled to make up the basal medium. (d) The inoculum was increased to $25 \%(\mathrm{v} / \mathrm{v})$ of total fermentation liquid. (e) All liquids were maintained at $40^{\circ}$ throughout, including rumen contents while being strained. When this straining was done at room temperature the subsequent protozoan starch storage was much slower. $(f)$ The working-up procedure was modified to enable an appreciable part of the starch-filled protozoa to be quickly isolated. Fermentations were carried out in 2-litre Buchner flasks, four at a time, and $30 \mathrm{~min}$. after the last shaking the supernatant was carefully decanted and the residue, consisting mainly of the various protozoan bottom layers, was transferred to a number of $\mathbf{5 0} \mathrm{ml}$. separating funnels with short stems. After standing for $20 \mathrm{~min}$. the bottom white layers in each were drawn off into boiling-tubes, and the heavy protozoa therein washed with distilled water, by decantation. The subsequent bursting of the cells with Teepol XL and the collection of starch granules was carried out as previously described (Oxford, 1951) save that a temperature of $50^{\circ}$ was used. Not all the holotrich starch was isolated by this rapid procedure, but by rigid standardization of conditions it was hoped that yields in successive fermentations could be fairly compared.

Carbohydrate fermentations without appreciable bacterial competition. Owing to the slowness of their deposition and the difficulty of washing them free from bacteria it was not found practicable to carry out fermentations with washed total protozoa from muslin-strained rumen liquor (2 1.) but only with a small fraction of relatively bacteria-free protozoa. Quite a fair proportion of the total ciliates of the sample of rumen contents strained were, however, left on the muslin together with plant residues, and these protozoa were 
resuspended in the basal salt medium (Elsden, 1946) with acetate at $40^{\circ}$ and separated from plant debris by re-straining. When this filtrate was allowed to stand the protozoa sank to the bottom quite rapidly, since the basal medium is less dense and viscous than rumen liquor. They could then be quickly collected, relatively free from bacteria, by decanting the supernatant. The usual procedure was to wash the residue on the muslin twice, combine the two protozoan layers so obtained, and make up to $150 \mathrm{ml}$. with basal medium. After thorough mixing, $75 \mathrm{ml}$. of this suspension were added to each of two $250 \mathrm{ml}$. Buchner flasks containing $700 \mathrm{mg}$. of glucose (or fructose) and the carbohydrate to be tested, respectively, dissolved in a little basal medium. After filling each flask with the basal medium the subsequent fermentation procedure was exactly as described above. Provided the fermentation was not allowed to proceed beyond $4-5 \mathrm{hr}$. no overwhelming turbidity due to bacterial growth developed. The same procedure was also used for the washed protozoa obtained direct from strained rumen liquor. When a polysaccharide was to be fermented it was first dissolved in a little warm water before addition of the inoculum.

Isolation of protozoan starch from rumen contents of normally grazing sheep. Glucose fermentations carried out with strained rumen contents from sheep slaughtered after grazing for some weeks on Spring grass led to no useful results, at least as far as protozoa were concerned. The fermentations proceeded with uncontrollable violence and owing to the physical properties of the rumen fluid did not result in the separation of a white protozoan bottom layer. Microscopical examination of the strained rumen liquor having shown that there was a rich fauna of iodophilic ciliates, the method of Pucher, Leavenworth \& Vickery (1948), involving perchloric acid extraction of the starch, was directly applied to the residue remaining after steam-bath evaporation of strained liquor obtained by working up rumen contents within a few hours of slaughter, followed by drying in vacuo. Instead of $250 \mathrm{mg}$. of residue material as recommended, ten times this amount was used in each determination, in order to make possible the working up of the entire rumen contents. The perchloric acid method was also applied to various protozoan fractions obtained from hay-fed sheep; in these instances the method of Pucher et al. was not modified.

Substrates. The following substances were used: fructose (glucose free), galactose, mannose, rhamnose, xylose, arabinose, lactose, trehalose (Laboratory Reagent Quality; British Drug Houses Ltd.); glucose, soluble starch, lactic acid (British Drug Houses Ltd., Analar chemicals); dihydroxyacetone, ribose, raffinose, glucosamine hydrochloride (L. Light \& Co.); maltose (Hopkin \& Williams; and Thomas Kerfoot \& Co., Biochemical Reagent quality). In view of the importance of the cellobiose fermentation three different specimens of this sugar were employed (British Drug Houses, Ltd.; L. Light \& Co.; Thomas Kerfoot \& Co., Biochemical Reagent quality). The sucrose used was ordinary household sugar.

One specimen of bacterial levan was newly prepared by growing Bacillus megatherium A.T.C.C. 697 on the liquid sucrose medium of Tarr \& Hibbert 
(1931). It was purified by two ethanol precipitations and yielded less than $1 \%$ of glucose on hydrolysis. Another specimen, at least 8 years old and prepared similarly, was also available. Purified inulin was a gift from the Edinburgh University Chemical Department.

\section{RESULTS}

Evidence in favour of regarding the 'iodophilic polysaccharide granules' of rumen protozoa as starch. According to Pucher et al. (1948) the iodine complex of starch, but not that of glycogen, is precipitated in presence of $6 \%$ sodium chloride. They extracted the polysaccharides from plant and animal material by the perchloric acid method of Nielsen (1943). By means of these procedures the best dried protozoan polysaccharide granule preparations obtained previously (Oxford, 1951) were found to contain at least $70 \%$, the granulefilled protozoa (c. $1 \% \mathrm{~N}$ content) at least $60 \%$, and other protozoan preparations (c. 4 and $5 \% \mathrm{~N}) 50$ and $40 \%$, respectively, of 'starch' in the above sense. It is, therefore, justifiable to refer tentatively to the protozoan storage polysaccharide as starch, rather than glycogen, although a final decision must await the results of detailed structural studies now being carried out elsewhere. As shown later, both holotrichs and oligotrichs contain 'starch' in the Pucher et al. sense of the term.

Preparation of holotrich starch in quantity by fermentation of glucose by whole rumen liquor. This experiment continued for three months, with withdrawal of rumen contents $(1 \mathrm{l}$.) from each of two fistulated sheep three times a week. The muslin-strained rumen liquid was used directly as inoculum, and starch granules were liberated from the holotrich ciliates in the washed protozoan white bottom deposits left after glucose fermentation, by the action of Teepol. Care was taken to exclude as much protozoan debris and unburst protozoa as possible from the final dried product. The mean yield from 33 separate fermentations was $1.45 \mathrm{~g}$. (extremes 0.4 and $2 \cdot 2 \mathrm{~g}$.). The lowest yield was obtained in the 9th fermentation, after which the sheep were given one week's rest. Thereafter, the starch yield was well maintained, the final (33rd) yield being $1.56 \mathrm{~g}$. of which $70 \%$ came from the protozoa supplied by sheep No. 272. During the course of this starch accumulation, opportunity occurred of working up the whole rumen contents of two hay-fed sheep killed for another purpose. Each sheep afforded $c .3 \mathrm{l}$. of strained rumen liquor, and the respective holotrich starch yields were $\mathbf{1 \cdot 6}$ and $\mathbf{3 \cdot 6} \mathrm{g}$. With the kind of meadow hay fed to these sheep, the maximum yield of rumen holotrich starch seems, therefore, to be of the order of $1 \mathrm{~g}$./l. of rumen contents.

$Y$ ields of holotrich starch by fermentation of soluble carbohydrates by washed rumen protozoa. The whole range of sugars was first tested by means of washed protozoa obtained from the deposit on the muslin when rumen contents were strained (see under Methods). Less than $1 \mathrm{mg}$. starch $/ 100 \mathrm{mg}$. substrate was obtained in the following instances: dihydroxyacetone, xylose, arabinose, ribose, galactose, mannose, rhamnose, glucosamine, maltose, lactose, trehalose, raffinose, soluble starch (as paste), lactate, or when no 
substrate was provided. These results are regarded as completely negative. The positive results were obtained with glucose, fructose, sucrose, cellobiose, bacterial levan and inulin, and are summarized in Table 1. It will be seen that they vary from 4 to $7 \%$ with cellobiose to 18 to $24 \%$ with fructose, which, as previously noted (Oxford, 1951), appeared to be the best substrate for protozoan starch formation.

Table 1. Holotrich starch yields when well-washed protozoa fermented soluble carbohydrates

\begin{tabular}{|c|c|c|}
\hline $\begin{array}{l}\text { Carbohydrate } \\
\text { fermented }\end{array}$ & $\begin{array}{c}\text { Starch yields } \\
\text { in separate experiments } \\
(\%)\end{array}$ & $\begin{array}{l}\text { Mean starch } \\
\text { yield } \\
(\%)\end{array}$ \\
\hline Glucose & $11,13,17,19,20,21$ & 17 \\
\hline Fructose & $18,21,24$ & 21 \\
\hline Sucrose & $6,11,14$ & $10 \cdot 3$ \\
\hline Cellobiose & 4, 6, 6 (Kerfoot); 7, 7 (B.D.H.); 4 (Light) & $5 \cdot 7$ \\
\hline Inulin & 21 & 21 \\
\hline Bacterial levan & 10 (old); 19 (new) & 14.5 \\
\hline
\end{tabular}

The surprising result that sucrose and cellobiose were the only disaccharides utilized for starch formation was confirmed by using washed protozoa from strained rumen liquor as inoculum. In each experiment two disaccharides were compared side by side or else a disaccharide was compared with a control containing no substrate. The results, summarized in Table 2, in every way confirmed those in Table 1.

Table 2. Holotrich starch formation from disaccharides

\begin{tabular}{|c|c|c|c|c|c|c|}
\hline \multirow[b]{2}{*}{$\begin{array}{c}\text { Sugars } \\
\text { compared }\end{array}$} & \multicolumn{6}{|c|}{ Yield of holotrich starch (mg./700 mg. sugar supplied) from } \\
\hline & $\begin{array}{c}\text { Sucrose } \\
\text { S }\end{array}$ & $\begin{array}{c}\text { Cellobiose } \\
\text { C }\end{array}$ & $\begin{array}{c}\text { Lactose } \\
\quad \text { L }\end{array}$ & $\begin{array}{c}\text { Maltose } \\
\mathbf{M}\end{array}$ & $\underset{\mathbf{T}}{\text { Trehalose }}$ & $\begin{array}{c}\text { No } \\
\text { substrate } \\
\mathbf{N}\end{array}$ \\
\hline $\mathbf{S} \mathbf{v} \mathbf{N}$ & 330 & - & - & - & - & 30* \\
\hline & 320 & & 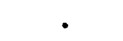 & $\cdot$ & • & 40*** \\
\hline S v. C (Kerfoot) & 230 & 133 & . & . & . & . \\
\hline C (Kerfoot) v. L & . & 95 & $\mathbf{5}$ & . & . & . \\
\hline C (Light) v. M & . & 110 & . & 10 & . & . \\
\hline C (Kerfoot) v. M & & 210 & . & 40 & . & . \\
\hline S v. T & 220 & . & . & . & $\mathbf{3 0}$ & . \\
\hline Mean yield & 275 & 137 & 5 & 25 & 30 & 35 \\
\hline
\end{tabular}

- Protozoa worked up at end of fermentation period.

** Protozoa worked up at beginning of fermentation period.

In every instance the isolated starch was compared with that obtained by glucose fermentation with respect to granule shape and size, and colour given with iodine. It was evident that the same substance was always obtained, no matter whether the structural unit given as substrate was glucose or fructose, or both. 
The starch of rumen oligotrich ciliates. In spite of many experiments made to obtain a suspension of iodophilic oligotrichs unmixed with holotrichs and their starch grains, only one method of limited application has so far been devised, namely, fermentation of glucosamine hydrochloride for 5-6 hr. by washed protozoa. The holotrichs thereby disappeared completely as organized structures, for reasons at present unknown, and when the bottom protozoan layer was isolated and washed by decantation, a greyish (not white) deposit was obtained which consisted chiefly of iodophilic Diplodinium with some Entodinium. When the fermentation was prolonged overnight the oligotrichs in turn were no longer particularly iodophilic.

An iodophilic preparation so obtained was dried in vacuo at room temperature $(50 \mathrm{mg}$. from $1 \mathrm{l}$. rumen contents) and then submitted to the starch isolation procedure of Pucher et al. (1948). A 7.4\% yield of almost white starch was obtained, completely soluble in hot water. It gave a purple colour with iodine, almost indistinguishable from that given by holotrich starch; the oligotrich starch colour was perhaps a shade bluer in tone. The iodophilic oligotrichs were also sufficiently fragile to be burst by Teepol with starch liberation.

Although an increase in the number of iodophilic oligotrich ciliates is plainly revealed by microscopic examination during the course of a glucose or fructose fermentation, there was no such increase when cellobiose was the substrate. Only the holotrichs became filled with starch grains in this instance.

The starch of rumen contents of grass-fed sheep. The sward consisted chiefly of ryegrass and clovers. In all three sheep killed, there was a rich rumen micro-fauna consisting largely of oligotrichs, although holotrichs were also plentiful. The glycogen-containing pseudo-yeasts, and the large starchcontaining 'cigar-shaped bacilli' of van der Wath (1948) were also present in great numbers. The isolated 'starch' in Table 3 may not, therefore, consist entirely of ciliate starch, even assuming that no starch from the fodder was present in the rumen. This is probably true for the second sheep killed early in June, but is not so certain for the one killed in August. All specimens of isolated starch gave a purple colour with iodine.

Table 3. Starch extraction from rumen contents of grass-fed sheep

\begin{tabular}{|c|c|c|c|c|c|c|}
\hline \multirow[b]{2}{*}{$\begin{array}{l}\text { Date of slaughter } \\
\text { of sheep }\end{array}$} & \multirow[b]{2}{*}{$\begin{array}{c}\text { Period of } \\
\text { grazing } \\
\text { (days) }\end{array}$} & \multirow[b]{2}{*}{$\begin{array}{c}\text { Carcase } \\
\text { weight } \\
\text { (lb.) }\end{array}$} & \multirow[b]{2}{*}{$\begin{array}{l}\text { Weight of } \\
\text { rumen } \\
\text { contents } \\
\text { (g.) }\end{array}$} & \multicolumn{3}{|c|}{$\begin{array}{l}\text { Weight of } \\
\text { solids (S) }\end{array}$} \\
\hline & & & & $\begin{array}{l}\text { Volume of } \\
\text { strained } \\
\text { rumen } \\
\text { liquor } \\
\text { (ml.) }\end{array}$ & $\begin{array}{c}\text { by } \\
\text { evaporation } \\
\text { of strained } \\
\text { rumen liquor } \\
\text { (g.) }\end{array}$ & $\begin{array}{c}\text { Starch } \\
\text { in } \mathrm{S} \mathrm{by} \\
\mathrm{HClO}_{4} \\
\text { extraction } \\
(\%)\end{array}$ \\
\hline $23 / 5 / 1950$ & 18 & - & 5823 & 2448 & - & $\begin{array}{l}(0.45 \mathrm{~g} .)^{*} \\
0.9\end{array}$ \\
\hline $6 / 6 / 1950$ & 32 & 63 & 4860 & 2600 & 162 & $\begin{array}{l}1.05 \\
0.9\end{array}$ \\
\hline $1 / 8 / 1950$ & 88 & 56 & 5330 & 2450 & $97 \cdot 2$ & $\begin{array}{l}0 \cdot 6 \\
0 \cdot 6\end{array}$ \\
\hline
\end{tabular}

* By direct isolation of holotrich ciliates and subsequent bursting by Teepol. 


\section{DISCUSSION}

The main interest of the results on the protozoan fermentation of soluble sugars centres in the ability of the holotrich ciliates to form starch from cellobiose. The fact that the levans are also suitable substrates for starch formation is not so surprising in view of the fact that invertase is known to attack them (cf. Archbold, 1940), and the probability that these protozoa must have a very active invertase, since sucrose appears to be as suitable as glucose with respect to starch formation. It would seem that the holotrichs must contain the enzyme cellobiase (but not, however, maltase), since it is inconceivable that starch can be built up directly from cellobiose. The researches of Hungate (1950) have established a close connexion between cellulose and cellobiose fermentation by rumen bacteria, so that if it be accepted that rumen protozoa can also attack cellulose' (i.e. by ingestion followed by enzymic digestion of plant particles) it follows that they ought to be able to attack cellobiose. Unfortunately for this line of reasoning, those ciliated protozoa with very small mouths which ought not, and by microscopic examination clearly do not, ingest plant particles to any extenit, namely, the holotrich ciliates, are the very ones which appear to contain cellobiase, whereas the oligotrich ciliates, which are very active in ingesting plant particles, do not appear to be able to utilize cellobiose for the formation of their starch-like reserve polysaccharide. The alternative hypothesis, that when the cellulose of plant particles in the rumen is being attacked by bacteria, there may be local pockets of soluble sugars including cellobiose near these particles, would, therefore, appear to merit further consideration. The extreme motility and water-passing properties of the holotrich ciliates would at least enable them to take advantage of suitable soluble sugars to be found anywhere in the rumen contents, provided bacterial competition were not too great. As shown previously (Oxford, 1951). this competition is not too great when glucose, fructose or sucrose is fermented but must be serious in the case of cellobiose since no appreciable starch formation by holotrich ciliates took place when that sugar was fermented by whole rumen liquor. It is only when the protozoa are freed as far as possible from bacteria that their utilization of cellobiose can be demonstrated. Even then, however, the other disaccharides tested are useless to the protozoa. The fact that maltose appears to be of no use to the protozoa for starch formation is surprising, and may indicate that the well-known phosphorylating mechanism for starch production is active here also. Our observations certainly do not support the claims of Trier (1926) or of Wieneck (1934) that lactose is converted into 'glycogen' by rumen ciliates, nor those of van der Wath (1942) that maltose is similarly utilized.

In view of the activity of the holotrich ciliates in converting bacterial levan and inulin into starch in vitro, it is surprising that the rumens of sheep fed on Spring grass, which is known to contain far more soluble sugars than hay and in particular soluble levans (see Norman, 1936), do not contain more holotrich starch than the small amounts reported in Table 3. Spring grass, being rich in soluble protein also, would appear to encourage the growth of 
the oligotrich ciliates preferentially, a fact already noted by Mangold (1929). With hay-fed sheep, however, the rumen holotrich ciliates become of relatively greater importance, and a clear indication of the suitability of this environment for them lies in the fact that even when a volume of rumen contents equal to the whole is withdrawn in three equal instalments during the course of a week, the holotrich population remains approximately constant over many months, as shown by the starch yields obtained during glucose fermentation by strained rumen liquor in vitro.

It may be emphasized that one purpose of this paper has been to show that, from a biochemical point of view, it is inadvisable to group all the rumen ciliates together with respect to their biochemical activities. For example in the paper by Burroughs, Frank, Gerlaugh \& Bethke (1950) on cellulose fermentation by rumen contents in vitro, it is vaguely stated that some of the larger types of protozoa failed to survive throughout the entire series of fermentations. Since the two great groups of rumen ciliates (i.e. holotrich and oligotrich) are easily distinguished in unstained preparations, even with the $2 / 3$ in. objective, it is to be hoped that a distinction will henceforward be made between them in all such fermentation studies with rumen contents.

It is a pleasure to thank the following for their aid: our colleague Mr P. J. Heald for confirming that our bacterial levan contained no glucose and for allowing us to use the rumen contents of his slaughtered hay-fed sheep; Messrs W. Thomson and J. C. Gill of this Institute for providing the grazing sheep; Professor E. L. Hirst, F.R.S. and Dr E. G. V. Percival of Edinburgh University for the gift of a specimen of highly purified inulin, for drawing our attention to the Pucher et al. method of starch extraction, and for accepting our fifty-gram specimen of holotrich starch with a view to determining its detailed chemical constitution; and to Dr D. M. Webley of the Macaulay Institute for the culture of B. megatherium.

\section{REFERENCES}

Archiold, H. K. (1940). Fructosans in the monocotyledons. New Phytol. 39, 185.

Burroughs, W., Frank, N. A., Gerlaugh, P. \& Bethke, R. M. (1950). Preliminary observations upon factors influencing cellulose digestion by rumen microorganisms. J. Nutrit. 40, 9.

Doyle, W. L. (1943). Nutrition of Protozoa. Biol. Rev. 18, 119.

Elsden, S. R. (1946). The fermentation of carbohydrates in the rumen of sheep. J. exp. Biol. 22, 51.

Hungate, R. E. (1950). The anaerobic mesophilic cellulolytic bacteria. Bact. Rev. $14,1$.

Kudo, R. R. (1947). Protozoology, 3rd ed. Springfield, Ill.: Charles C. Thomas.

MANGOLD, E. (1929). Handbuch der Ernährung und des Stoffwechsels der Landwirtschaftlichen Nutztiere. Berlin: J. Springer.

Nielsen, J. P. (1943). Rapid determination of starch. An index to maturity in starchy vegetables. Industr. Engng. Chem. Anal. Ed. 15, 176.

Norman, A. G. (1936). The composition of forage crops. 1. Rye grass. Biochem. $J$. 30, 1354.

Oxford, A. E. (1951). The conversion of certain soluble sugars to a glucosan by holotrich ciliates in the rumen of sheep. J. gen. Microbiol. 5, 83.

Pucher, G. W., Leavenworth, C. S. \& Vickery, H. B. (1948). Determination of starch in plant tissues. Anal. Chem. 20, 850. 
TARR, H. L. A. \& HrbBert, H. (1931). Formation of dextran by Leuconostoc mesenteroides. Canad. J. Res. 5, 414.

Trier, H. J. (1926). Carbohydrate metabolism of rumen infusoria and the importance of green plant particles for these organisms. Z. vergl. Physiol. 4, 305.

WATH, J. G. VAN DER (1942). Studies on the alimentary tract of the merino sheep with special reference to the role of the ruminal micro-fauna and flora. Thesis. Univ. of Pretoria.

WATH, J. G. VAN DER (1948). Studies on the alimentary tract of merino sheep in South Africa. XI. Digestion and synthesis of starch by ruminal bacteria. Onderstepoort J. vet. Sci. 23, 367.

WiEneck, E. (1934). Cellulose digestion in the ciliates of the rumen. Arch. Protistenk, $82,169$.

(Received 28 August 1950) 